\title{
ESTUDOS DE FREQÜÊNCIA, MORFOLOGIA E DIAGNÓSTICO DE ENTAMOEBA GINGIVALIS, GROS, 1849
}

\author{
Silvio Favoreto Junior e Maria Inês Machado
}

\begin{abstract}
Realizamos estudos de freqüencia de Entamoeba gingivalis entre 100 pacientes atendidos nos ambulatórios odontológicos da Universidade Federal de Uberlândia (UFU), utilizando-se esfregaços corados pela técnica de Papanicolaou modificado, revelando um expressivo indice de $62 \%$ de positividade. A afinidade do corante pelo conteúdo vacuolar fagocítico impede uma nítida visualização das cromatinas central e periférica do núcleo do parasita. Lauados bucais de outros 10 pacientes foram utilizados para avaliar em qual método parasitológico de diagnóstico (a fresco e em coloraçāo por bematoxilina férrica, Giemsa e Papanicolaou) ocorre melbor visualização do parasita. O exame a fresco do sedimento do lavado bucal revelou $100 \%$ de positividade e nítida visualização do parasita. Nenbuma técnica de coloração dos esfregaços se mostrou adequada, apresentando o núcleo freqüentemente mascarado pelos vacuiolos fagocíticos. Em preparações coradas por azul de toluidina e na microscopia eletrônica de transmissão pode-se observar caracteres morfológicos típicos do protozoário.
\end{abstract}

Palauras-chaves: Entamoeba gingivalis. Protozoârios orais. Doença periodontal. Diagnóstico estomatológico.

$\mathrm{Na}$ cavidade oral humana encontram-se populações microbianas polimórficas, constituídas principalmente por bactérias, leveduras, partículas virais, micoplasmas e apenas dois protozoários: Entamoeba gingivalis e Trichomonas tenax.

Durante a transferência interpessoal dessa população microbiana ocorre a troca de pelo menos, 10 mil unidades de Porpbyromonas gingivalis, o principal agente da periodontite, 500 mil unidades da bactéria Streptococcus mutans, o maior causador da cárie, e outras centenas de milhares de lactobacilos, seus

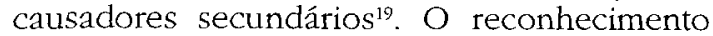
de que tanto a cárie como a gengivite e a periodontite são infecções passíveis de transmissão é pouco difundido, entretanto necessário na manutenção da saúde dos tecidos bucais.

O trofozoíto de E. gingivalis, única forma no ciclo vital do parasita, possui movimentação rápida através de pseudópodes lobosos, grandes e hialinos ${ }^{28}$. O núcleo possui estrutura característica do gênero.

O substrato para nutrição de E. gingivalis é composto basicamente de leucócitos, células

\footnotetext{
Departamento de Patologia da Universidade Federal de Uberlândia, Uberlândia, MG

Endereço para correspondência: Prof. Silvio Favoreto Junior. Depto. de Patologia/UFU. Av. Pará 1720, Campus Umuarama, 38400-902 Uberlândia, MG.

Recebido para publicação em 10/02/95
}

epiteliais e bactérias ${ }^{7}$. Segundo Wantland \& Wantland $^{27}$, E. gingivalis é capaz de executar citólise de eritrócitos e leucócitos. Rysky \& Sapelli $i^{22}$ afirmam que em $80 \%$ dos espécimes examinados havia eritrofagocitose.

Segundo Desowitz ${ }^{9}$, o protozoátio não está livremente distribuido na cavidade bucal e sim restrito aos acúmulos de placa dental. De modo geral, os autores consideram que o acúmulo de placa bacteriana e as patologias decorrentes deste fato propiciam o aumento da freqüência de $E$. gingivalis. Omnes ${ }^{18}$ estudando indivíduos com gengivas sadias observou no máximo $19,1 \%$ de casos positivos, enquanto nos individuos com patologia gengival apresentaram $51,9 \%$ de positividade para $E$. gingivalis. O mesmo autor afirma que o índice de positividade para protozoários orais aumenta com a diminuição da qualidade da higiene oral; no entanto, uma excelente higiene pode evitar, porém não exclui a possibilidade de contaminação. É consenso entre os autores que é necessário um substrato sólido (órgão dental ou próteses) para que $E$. gingivalis se estabeleça ${ }^{5}$.

Quanto à freqüência, Rousset \& Lauvergeat ${ }^{21}$, estudando 250 adultos jovens em Paris, detectaram $11,1 \%$ de indivíduos parasitados que afirmam jamais terem mantido contato labial; Takada ${ }^{23}$ descreve o encontro de $6,5 \%$ de indivíduos parasitados em idade escolar e $14 \%$ entre pacientes odontológicos 
Favoreto Junior S, Machado MI. Estudos de freqüência, morfologia e diagnóstico de Entamoeba gingivalis, Gros, 1849. Revista da Sociedade Brasileira de Medicina Tropical 28:379-387, out-dez, 1995.

na cidade de Osaka, no Japão. É sabido que boa parte da população oriental pratica, com restriçōes, o ato erógeno do contato labial. Esses dados demonstram que pode ocorrer o processo de contágio imediato. Compartilhar alimentos, copos ou talheres pode ser uma importante fonte de infecção, pois segundo Desowitz', os trofozoítos de $E$. gingivalis sobrevivem até 48 horas a $15^{\circ} \mathrm{C}$ e são moderadamente resistentes à dessecação.

Não observamos, na literatura consultada, dados consistentes de que a infecção tenha preferência por sexo, no entanto a idade parece ser o fator mais importante na epidemiologia de $E$. gingivalis. Normalmente, observa-se significativo aumento de positividade após a faixa etária de 15 anos $^{6}$.

Alguns autores consideram a possibilidade de $E$. gingivalis estar envolvida na etiologia das doenças periodontais. Afirmação que se fundamenta no relato de melhora do quadro gengival após o uso de drogas de conhecida eficácia amebicida como: hidrocloreto de emetina, um derivado da ipecacuanha ${ }^{16}$ e o metronidazole ${ }^{1-1}$. Lyons \& Scholten ${ }^{16}$ aventam a hipótese de $E$. gingivalis carrear partículas virais no seu citoplasma ou incrustadas no genoma amebiano servindo como veículo para a infecção viral.

Vários métodos de diagnóstico de $E$. gingivalis são descritos, diferindo quanto à sensibilidade e consenso de eficácia. A maioria dos autores descreve a cultura in vitro como método eficaz para detecção do parasita; outros, defendem a utilização de esfregaços corados por diferentes técnicas e outros, ainda, se utilizam de exames a fresco de material obtido por lavado bucal 3681011 .

Quanto aos protozoários orais, após quase dois séculos da descrição de ambos os parasitas, são ainda hoje pouco esclarecidas as questões relativas à epidemiologia, biologia, morfologia e diagnóstico desses organismos especialmente $E$. gingivalis, daí nosso interesse pela parasitologia oral bem como sua correlação com a saúde bucal.

\section{MATERIAL E MÉTODOS}

População estudada. A população estudada foi dividida em dois grupos: o grupo I, constituído de 100 pacientes e o grupo II, constituído de 10 pacientes; ambos, procedentes dos serviços de Pronto Socorro (PSO) e Ambulatório Odontológico da
Faculdade de Odontologia da Universidade Federal de Uberlândia, no período de julho de 1990 a março de 1993. Todos os pacientes foram submetidos à investigação clínica $e$ epidemiológica. O estado periodontal e índice de higiene oral foram avaliados utilizando-se os critérios de Russell modificados por Rigueira ${ }^{19}$.

Colbeita e análise parasitológica das amostras. No grupo I, as amostras de placa bacteriana e matéria alba foram colhidas com swabs estéreis umedecidos em solução salina, os quais foram friccionados em quatro diferentes sítios da cavidade oral: crista marginal da gengiva superior, crista marginal da gengiva inferior, dentes portadores de processo carioso e região dorsal da língua. Para cada sítio de colheita foram confeccionados esfregaços em duplicata, cotados pela técnica de papanicolaou modificada ${ }^{10}$. A positividade para E. gingivalis foi indicada quanto da visualização de formas trofozoíticas do parasita por exame em microscopia ótica com imersão (Olympus $\mathrm{BH} 2$ ).

No grupo II, as amostras foram colhidas por bochecho de $3 \mathrm{ml}$ de soluçâo fisiológica, por no minimo 30 segundos. $\mathrm{O} \mathrm{pH}$ do lavado foi aferido imediatamente após a colheita e as amostras foram centrifugadas a $500 \mathrm{rpm}$ durante 5 minutos. Uma gota do sedimento obtido, disposta entre lâmina e lamínula, foi submetida ao exame parasitológico a fresco realizado no máximo 2 horas após a colheita. A positividade para E. gingivalis foi indicada quanto à visualização de formas trofozoíticas do parasita por exame parasitológico a fresco em microscopia ótica com aumento de 400 vezes, seguindo caracteres taxonômicos específicos, tais como: movimentação, tamanho, aspecto do citoplasma e emissão de pseudópodes. A cada exame, vinte formas livres e de locomoção foram fotografadas para posterior análise de mensuração.

Das amostras consideradas positivas, no exame parasitológico a fresco, foram confeccionados esfregaços em triplicata, fixados com solução de álcool polivinílico (PVA) e corados, sendo lâminas da mesma amostra submetidas a três diferentes colorações: Papanicolaou ${ }^{10}$, hematoxilina férrica ${ }^{11}$ e Giemsa ${ }^{8}$.

Análise morfológica de E. gingivalis em microscopia ótica e eletrônica de transmissão. 
Favoreto Junior S, Machado MI. Estudos de freqüencia, morfologia e diagnóstico de Entamoeba gingivalis, Gros, 1849. Revista da Sociedade Brasileira de Medicina Tropical 28:379-387, out-dez, 1995.

O sedimento das amostras positivas foi imediatamente fixado por 2 horas em solução Karnovsky ${ }^{22}$ e novamente submetidos à centrifugação a $500 \mathrm{rpm}$ por $5 \mathrm{~min}$. O sedimento foi solidificado pela adição de $1 \mathrm{ml}$ de Agar Noble 4\% liquefeito. Após a solidificação, o bloco foi recortado, e processado pela técnica clássica para microscopia eletrônica de transmissão utilizando resina Epon $812^{22}$. Cortes semiseriados de 2 micrômetros de espessura foram obtidos em um ultramicrótomo Ultracut a fim de localizar E. gingivalis no material incluído. Os cortes foram então corados com solução de azul de toluidina $(0,25 \%$ em borato de sódio a $1 \%$ em água destilada) e examinados. Após detecção do parasita foram feitos cortes ultrafinos processados para análise em microscópio eletrônico de transmissão (Zeiss EM 109).

Análise Estatística. Para análise estatística dos dados obtidos foram feitas combinações binárias de variáveis e utilização do índice de correlação de Pearson e teste qui quadrado $\left(\mathrm{X}^{2}\right)$

\section{RESULTADOS}

Estudos de freqüência. O percentual de freqüência global de $E$. gingivalis na população do grupo I foi de $62 \%$. Quanto à variável epidemiológica de sexo não houve variação estatisticamente significante entre o sexo masculino (68\%) e feminino (55,3\%).

Analisando o percentual de positividade do grupo I, em relação à idade, os pacientes na faixa etária de 11 a 20 anos apresentaram $76 \%$ de positividade, resultado. estatisitcamente significante quando comparado à freqüência dos pacientes de 0 a 10 anos $(p<0,05)$. As demais faixas etárias não apresentaram diferenças significativas (Tabela 1).

Tabela 1-Freqüência de E. gingivalis no gnupo I em função da idade.

\begin{tabular}{|c|c|c|c|c|c|}
\hline \multirow{3}{*}{ Idade } & \multirow{3}{*}{$\begin{array}{l}\text { Total de } \\
\text { examinados }\end{array}$} & \multicolumn{4}{|c|}{ Pesquisa de $E$ gingivalis } \\
\hline & & \multicolumn{2}{|c|}{ positivo } & \multicolumn{2}{|c|}{ negativo } \\
\hline & & $n^{9}$ & $\%$ & $\mathrm{n}^{\mathrm{o}}$ & $\%$ \\
\hline $0-10$ & 4 & 1 & 25,0 & 3 & 75.0 \\
\hline $11-20$ & 25 & 19 & 76,0 & 6 & 24,0 \\
\hline $21-30$ & 35 & 21 & 60,0 & 14 . & 40.0 \\
\hline $31-40$ & 20 & 11 & 55.0 & 9 & 45,0 \\
\hline $41-50$ & 10 & 6 & 60,0 & 4 & 40,0 \\
\hline $51-60$ & 3 & 2 & 66,7 & 1 & 33.3 \\
\hline $61-70$ & 2 & 2 & 100,0 & 0 & 0.0 \\
\hline $71-80$ & 1 & 0 & 0,0 & 1 & 100.0 \\
\hline
\end{tabular}

Quanto à higiene da cavidade oral, embora nenhum dos pacientes tenha alcançado o escore "excelente", observamos a presença de $E$. gingivalis, em todas as demais classificações, sem variação estatisticamente significante entre os escores (Tabela 2).

Tabela 2- Freqüencia de E. gingivalis no grupo I em funçâo do Indice de Higiene Oral (IHO)

\begin{tabular}{|c|c|c|c|c|c|}
\hline \multirow{3}{*}{$\mathrm{IHO}$} & \multirow{3}{*}{$\begin{array}{c}\text { Total de } \\
\text { examinados }\end{array}$} & \multicolumn{4}{|c|}{ Pesquisa de $E$, gingivalis } \\
\hline & & \multicolumn{2}{|c|}{ positivo } & \multicolumn{2}{|c|}{ negativo } \\
\hline & & $\mathrm{n}^{\mathrm{o}}$ & $\%$ & $n^{0}$ & $\%$ \\
\hline Excelente & 0 & 0 & 0,0 & 0 & 0,0 \\
\hline Bom & 23 & 12 & 52,0 & 11 & 48.0 \\
\hline Regular & 25 & 13 & 52,0 & 12 & 48,0 \\
\hline Ruim & 32 & 23 & 72,0 & 9 & 28,0 \\
\hline Péssimo & 20 & 14 & 70,0 & 6 & 30,0 \\
\hline
\end{tabular}

A Tabela 3 apresenta a distribuição de positividade de acordo com os sítios bucais analisados, onde não observamos variação significativa entre as diferentes regiões pesquisadas para a presença do parasita. A distribuição da freqüência de $E$. gingivalis entre diferentes categorias ocupacionais: estudantes $(60 \%)$, assalariados $(62,5 \%)$, donas de casa $(64 \%)$ e profissionais liberais (60\%) não havendo variação estatística entre os grupos $(\mathrm{p}>0,05)$.

Tabela 3 Freqüência de $\mathrm{E}$ gingivalis no gnupo I em função do Sítio Bucal Examinado (SBE)

\begin{tabular}{|c|c|c|c|c|c|}
\hline \multirow{3}{*}{ SBE } & \multirow{3}{*}{$\begin{array}{l}\text { Total de sítios } \\
\text { examinados }\end{array}$} & \multicolumn{4}{|c|}{ Pesquisa de E. gingivalis } \\
\hline & & \multicolumn{2}{|c|}{ positivo } & \multicolumn{2}{|c|}{ negativo } \\
\hline & & $\mathrm{n}^{\mathrm{o}}$ & $\%$ & $n^{2}$ & $\%$ \\
\hline Cárie & 100 & 29 & 29,0 & 71 & 71,0 \\
\hline Gengiva superior & 100 & 35 & 35.0 & 65 & 65,0 \\
\hline Gengiva inferior & 100 & 24 & 24,0 & 76 & 76,0 \\
\hline Língua & 100 & 27 & 27,0 & 73 & 73,0 \\
\hline
\end{tabular}

Métodos de identificação, estudo morfológico e diagnóstico parasitológico de $\mathrm{E}$. gingivalis. Para análise de identificação, morfologia e avaliação de métodos de diagnóstico foi utilizado o grupo II, onde todos os pacientes se mostraram portadores de $E$. gingivalis, pelo exame parasitológico direto a fresco. A identificação de formas trofozoíticas de E. gingivalis, revelou características taxonômicas específicas, relativas ao tamanho 
Favoreto Junior S, Machado MI. Estudos de freqüência, morfologia e diagnóstico de Entamoeba gingivalis, Gros, 1849. Revista da Sociedade Brasileira de Medicina Tropical 28:379-387, out-dez, 1995.

entre as formas livres (parasita não aderido ao vidro) e formas de locomoção (parasita aderido ao vidro) que variou na razão de $32 \mathrm{e}$ 70 micrômetros, respectivamente, nos 20 espécimes mensurados.

A velocidade na locomoção e tipo de pseudópode emitido foram observados em todos os espécimes e caracterizados como "emissão rápida", do tipo loboso e unidirecionais quando o parasita se apresentava na forma de locomoção e multidirecionais quando em forma livre. $O$ citoplasma foi distinguivel ao exame a fresco em ectoplasma hialino e endoplasma granuloso (Figuras 1a, 1b e 1c).

Nenhuma das técnicas de coloração dos esfregaços utilizadas mostrou-se adequada a visualização e identificação de E. gingivalis. As

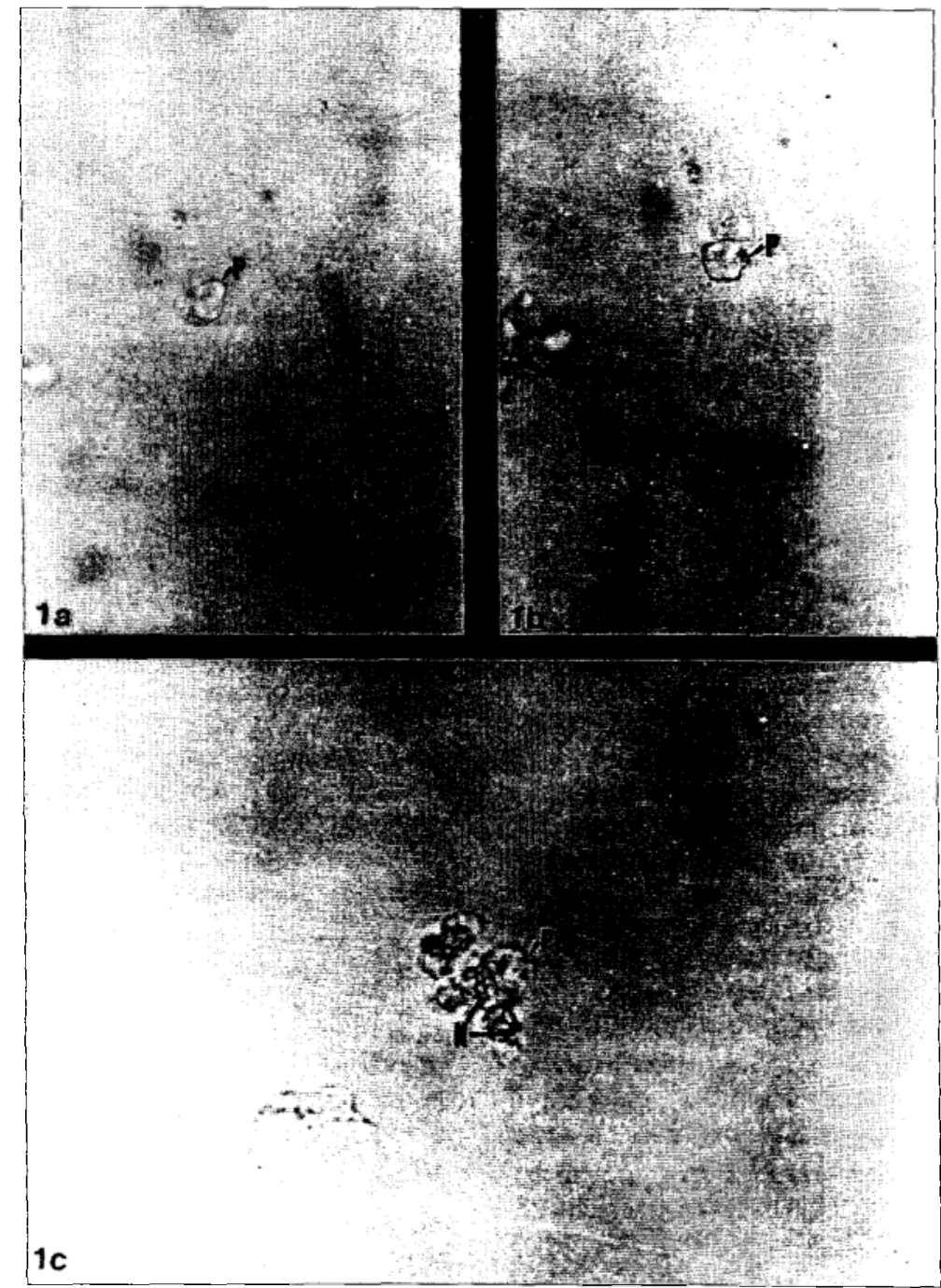

Figura 1a) E. gingivalis aderida ao vidro (forma de locomoça) ao exame parasitológico a fresco. Observar a emissão de pseudópodes $(P$ ). Fotomicrografia, exame à fresco, 120X; 1b) observação continuada, após 5 segundos, do mesmo campo demonstrado na Figura 1a. Notar modificacáo morfológica do protozoário indicando emissão e recolbimento de pseudópodes $(P)$. Fotomicrografia, exame a fresco, 120X.; 1c) E. gingivalis não aderidas ao vidro (formas livres) ao exame parasitológico a fresco. Observar núcleos (N) $e$ pseudópodes $(P)$ dos protozoários. Fotomicrografia, exame à fresco, $240 X$. 
Favoreto Junior S, Machado MI. Estudos de freqüência, morfologia e diagnóstico de Entamoeba gingivalis, Gros, 1849. Revista da Sociedade Brasileira de Medicina Tropical 28:379-387, out-dez, 1995.

técnicas de coloração de Papanicolaou, hematoxilina férrica e Giemsa apresentaram forte afinidade por vacúolos fagocíticos mascarando núcleo do parasita e dificultando o diagnóstico diferencial do amebídeo.

A observação em microscopia de luz dos cortes semifinos, após fixação e coloração com azul de toluidina, mostrou que E. gingivalis possuia, em média 29 micrômetros em seu maior eixo. No citoplasma observamos granulações fortemente coradas pelo azul de toluidina, núcleo bem definido, medindo em torno de 10 micrômetros de diâmetro, a cromatina periférica e o cariossoma bem evidentes, apresentando igual afinidade pelo corante, as demais áreas do núcleo eram predominantemente eucromáticas (Figuras $2 \mathrm{a}$ e 2b).

Em microscopia eletrônica de transmissão confirmamos a estrutura nuclear típica dos amebídeos, poucos ribossomas foram vistos aderidos aos complexos de membrana. No

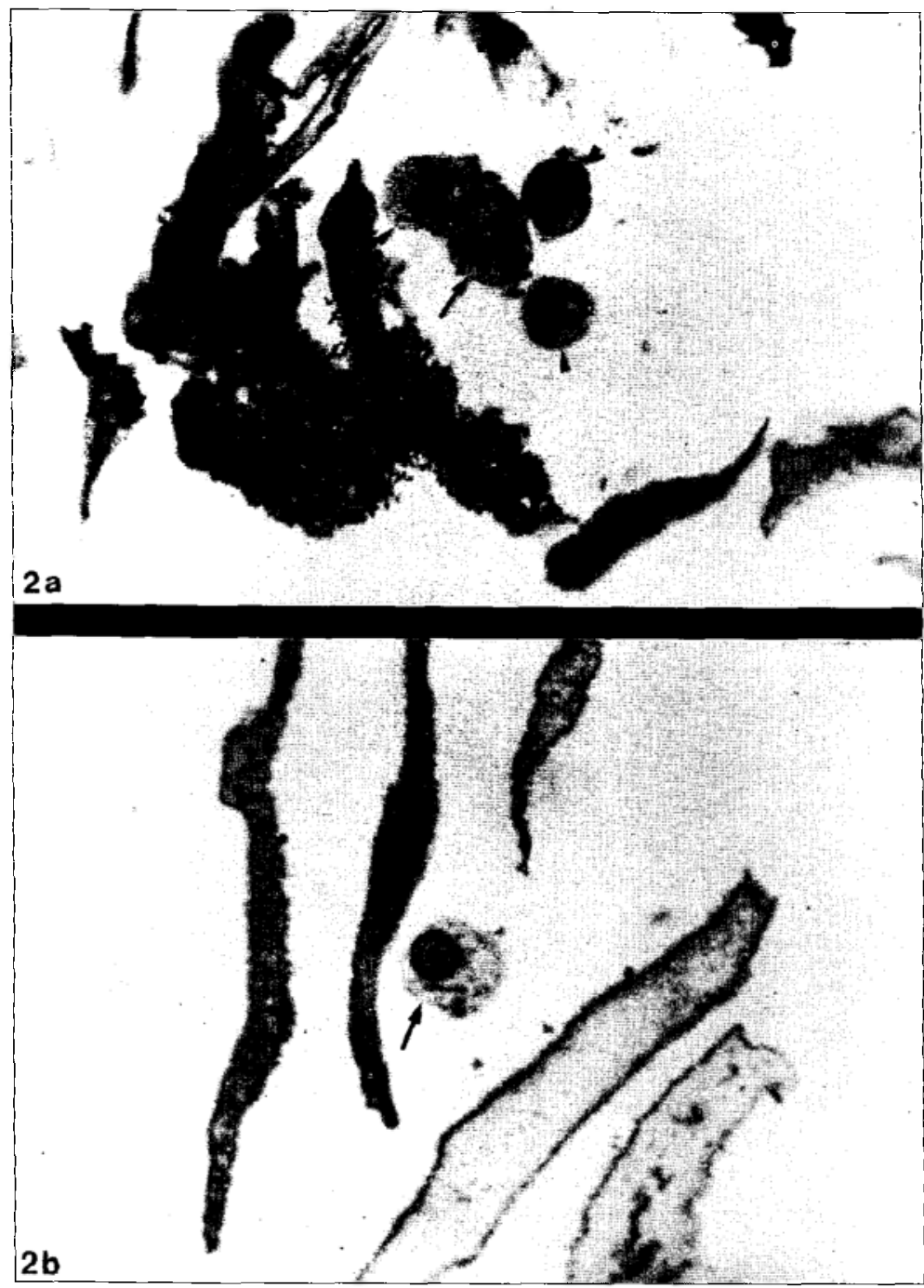

Figura 2a) No centro da figura, observar E. gingivalis com estrutura nuclear caracteristica. Circundando o protozoário bá células inflamatórias. Fotomicrografia, Epon 812, azul de toluidina, $560 \mathrm{X} ; 2 \mathrm{~b}$ ) E. gingivalis com estrutura nuclear característica e grânulos corados no citoplasma. Fotomicrografia, Epon 812, azul de toluidina, 850X. 
Favoreto Junior S, Machado MI. Estudos de freqüência, morfologia e diagnóstico de Entamoeba gingivalis, Gros, 1849. Revista da Sociedade Brasileira de Medicina Tropical 28:379-387, out-dez, 1995.

citoplasma foram observados vacúolos eletrondensos sugestivos de lisossomas $\mathrm{e}$ vacúolos contendo resíduos de estrutura nuclear de células fagocitadas, bactérias e material amorfo. Grânulos de glicogênio dispersos ou agrupados, aleatoriamente, foram observados no citosol. Retículo endoplasmático e complexo de Golgi típicos não foram identificados; poucas mitocôndrias possuíndo pequeno número de cristas eram presentes. A membrana plasmática, recoberta por glicocálice, apresentou projeçōes lobosas e filiformes (Figura 3).

\section{DISCUSSÃO}

O percentual de freqüência de parasitismo observado no grupo I foi superior aqueles anteriormente observados em nosso país ${ }^{112425}$. Cambom ${ }^{5}$ e Wantland \& Wantland ${ }^{27}$ nos

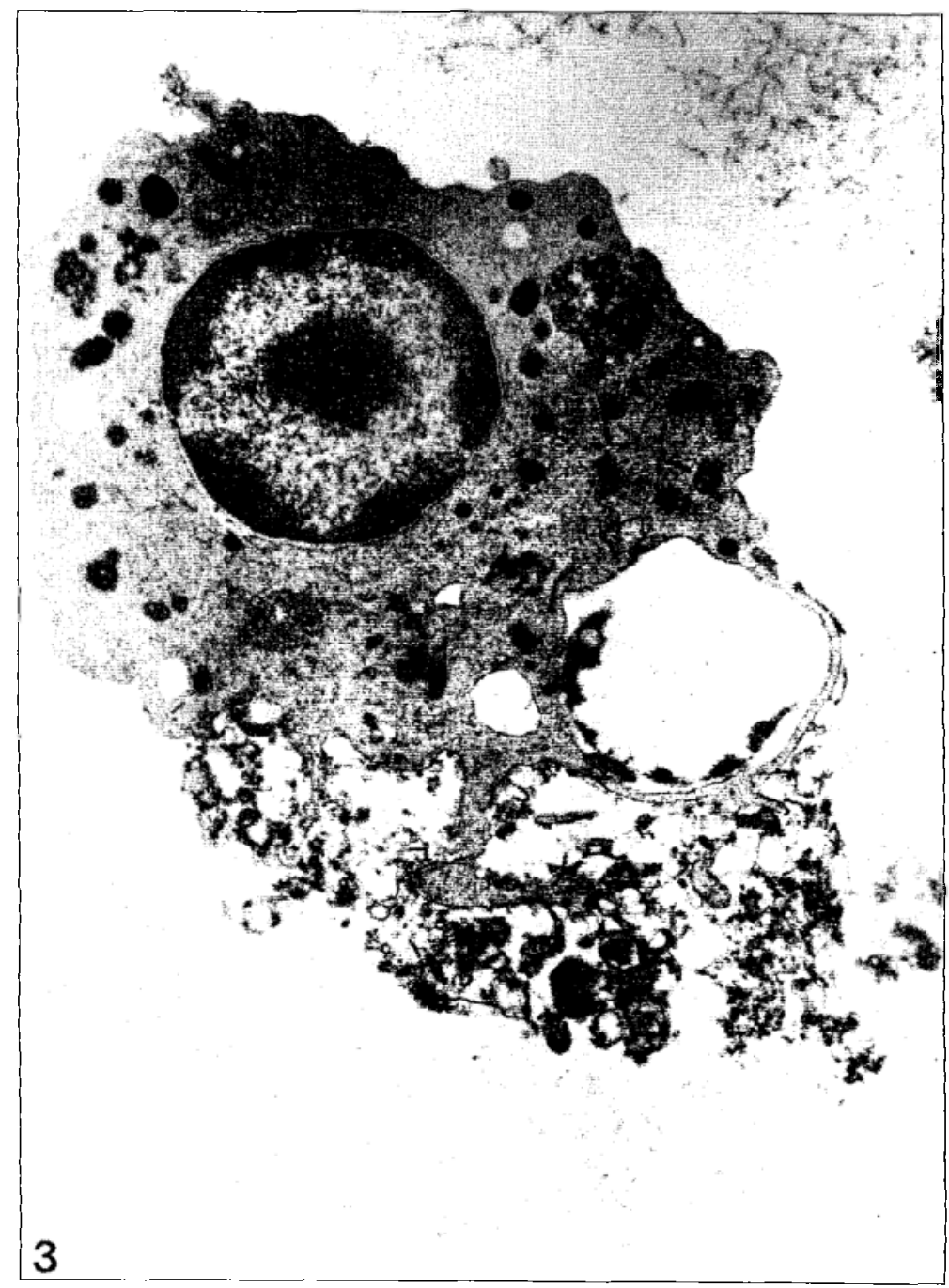

Figura 3 - E. gingivalis lista ao microscópio eletrônico. Notar estrutura nuclear caracteristica, grânulos eletrondensos, eletronlúcidos dispersos e fagossomas contendo material floculado que são vistos inclusos no citoplasma (quadrante superior direito da foto). No quadrante inferior direito pode-se observar fagossoma apresentando conteúdo em avançado estágio de digestão. Eletromicrografia, 16.000X. 
Favoreto Junior S. Macbado MI. Estudos de freqüência, morfologia e diagnóstico de Entamoeba gingivalis, Gros, 1849. Revista da Sociedade Brasileira de Medicina Tropical 28:379-387, out-dez, 1995.

chamam a atenção com relação aos percentuais de freqüência geral obtidos por diferentes autores (Rousset \& Lauverveat ${ }^{21}$, 29,6\%; Lapierre \& Rousset ${ }^{15}, 41,0 \%$; Cambom ${ }^{3}$, $86,4 \%$ e Feki \& Molet $^{16}, 32,7 \%$ ).

Entre 20 estudos selecionados no período de 1923 e 1993, desenvolvidos em diferentes paises, 9 mostraram prevalência acima de $50,0 \%$ e apenas 4 abaixo de $30,0 \%$. Este fato provavelmente se deve pela utilização de diferentes técnicas de diagnóstico empregadas pelos autores e pela diversidade de populações estudadas.

No presente estudo, embora os percentuais aumentem com a idade, os valores de postividade distribuídos nas faixas etárias de 0 a 80 anos, não demonstraram significância estatística. Apenas as correlações de freqüência na faixa etária dos 11-20 anos mostrou significância estatística quando comparada à faixa limítrofe inferior. A influência da idade sobre a presença de $E$. gingivalis é assinalada por diversos pesquisadores $23+1112172728$. A maioria deles está de acordo que a freqüência de $E$. gingivalis aumenta com o aumento da idade antigindo valores máximos proporcionais a partir de 20 anos.

Em nosso inquérito, a presença de $E$. gingivalis foi um pouco mais elevada no sexo masculino que no feminino, entretanto sem significância à nível estatístico. Dados coincidentes com o observado por Cechova ${ }^{6}$ $(53,01 \%$ para o sexo masculino e $50,45 \%$ para o feminino). A questão está em aberto, se a diferença relacionada ao sexo é um fator primário ou se há uma dependência secundária onde os níveis de higiene oral e o número de dentes variem entre homens $\mathrm{e}$ mulheres.

Quanto à higiene oral, considera-se que a população em estudo corresponde àquela que por vários motivos procura os serviços ambulatoriais e de Pronto Socorro, portanto não correspondendo a uma amostragem da população em geral ${ }^{6141620}$. Quanto à correlação entre a presença de E. gingivalis e o Índice de Higiene Oral não constatamos que freqüência de parasitismo esteja relacionada com a diminuição deste índice.

A maioria dos autores concorda que embora a qualidade da higiene dentária favoreça a implantação de $E$. gingivalis, esta não parece ser uma característica obrigatória, já que a freqüência é também alta em individuos com escore "bom" no Índice de Higiene Oral ${ }^{3}$.

Dentre os sítios bucais examinados, a gengiva superior mostra um percentual de freqüencia ligeiramente maior que os demais sítios; a nível estatístico, a pesquisa em vários sítios não é significativa na positividade para $E$. gingivalis. Resultado semelhante foi constatado por Gannon \& Linke ${ }^{10}$ que pesquisaram 32 locais da cavidade oral para a presença de $E$. gingivalis e concluíram não haver sítio específico para a colonização pelo protozoário.

A semelhança de nossos resultados, correlaçòes de freqüência de $E$. gingivalis com categorias profissionais têm sido procuradas sem conclusões significativas, mesmo em estudos com populações bastante diversificadas ${ }^{23} 26$.

Os 10 pacientes do grupo II foram utilizados para os estudos de diagnóstico em nosso inquérito, onde optamos pela padronização de uma variante do exame parasitológico a fresco, diferindo da técnica clássica, pela utilização do lavado bucal para colheita do material a ser pesquisado. Esta variação mostou-se excelente para a nítida visualização do parasita. Como já demonstrado $^{10}$ não há sítio preferencial para localização de E. gingivalis na cavidade bucal. Esta condição permite recomendar a utilização da técnica do lavado bucal para a pesquisa direta e diagnóstico do protozoário baseado na simplicidade da técnica, rapidez na obtenção do resultado específico e a alta sensibilidade.

Não observamos vantagem na utilização de esfregaços corados, pois freqüentemente os corantes nucleofílicos apresentavam grande afinidade pelos vacúolos fagocíticos, fato em parte explicado pela fagocitose de núcleos de leucócitos por $E$. gingivalis, impossibilitando sua identificação. Neste estudo não encontramos formas que indicassem tratar-se de cistos, dados concordantes com o observado na literatura ${ }^{1013}$

A grande diferença entre os diâmetros médios encontrados nas formas livres e de locomoção é coerente, já que, para locomoção é necessária adesão e conseqüente espraiamento do protozoário. O padrão de emissão de pseudópodes assemelha-se ao descrito por Wantland \& Wantland ${ }^{27}$.

A observação de $E$. gingivalis em cortes semifinos mostrou que a técnica não gerou 
Favoreto Junior S, Machado MI. Estudos de freqüência, morfologia e diagnóstico de Entamoeba gingivalis, Gros, 1849. Revista da Sociedade Brasileira de Medicina Tropical 28:379-387, out-dez, 1995.

alterações no tamanho e aparência do protozoário, preservando as medidas semelhantes à forma livre observada no exame à fresco. O grau de nitidez na visualização do parasita, com a utilização deste método, corrobora com a sua indicação para o estudo morfológico em microscopia ótica de $E$. gingivalis.

A morfologia a nível ultra-estrutural revelou cariossoma bastante evidente porém indicando função diferente do nucléolo nos eucariotos superiores já que a quantidade de ribossomas era bastante reduzida; esta hipótese é suportada pelos estudos de Wollaughin \& Aley $^{29}$ em Entamoeba bistolytica. Os grânulos eletrondensos são sugestivos de lisossomas, no entanto a falta de maquinaria específica para sua produção dificulta a interpretação e indica existência de vias exclusivas na produção de enzimas líticas. A presença de poucas mitocôndrias possuindo pequeno número de cristas sugere que E. gingivalis possui metabolismo microaerófilo, dado consubstanciado por Gannon \& Linke ${ }^{10}$. Os grânulos de glicogênio no citoplasma evidenciam que a principal fonte de energia seja a glicose, a semelhança do que ocorre em $E$. histolytica $a^{29}$. O delgado glicocálice, também observado por outros autores ${ }^{13}$ pode estar relacionado com a virulência no processo de adesão do protozoário ao substrato ${ }^{29}$. As projeções lobosas da membrana indicam a emissão de pseudópodes, enquanto as filiformes podem estar associadas ao processo de exocitose do parasita ${ }^{29}$.

Os dados relatados sobre a epidemiologia, diagnóstico, morfologia e aspectos fisiológicos, derivados destas observações, podem contribuir para o esclarecimento da biologia deste intrigante protozoário, conduzindo a estudos posteriores para o melhor entendimento de $E$. gingivalis e sua influência na saúde da cavidade oral.

\section{SUMMARY}

Entamoeba gingivalis is found only in its trophozoite form and it is postulated that its main transmission mechanism is through the kiss. E. gingivalis is considered pathogenic by some authors and commensal to others. It does not have a defined role in the installation of disease. To address some of this questions we studied a 100 patients who were seen through the Odontological Hospital from the Universidade Federal de Uberlândia in order to determine its frequency in the buccal cavity. The material were collected using swabs from four different buccal sites and the smears were stained by a modified Papanicolaou technique. The results revealed positivity index of $62 \%$. The affinity of the dye to the food vacuole contents and to the ingested bacterias prevents clear visualisation of the central and peripherical chromatin constituents of the parasite's nucleus. Mouth washes with 3 ml of saline from 10 patients, were used to evaluate which parasitological method of diagnosis (fresh, ironbaematoxylin stained, Giemsa and Papanicolaou) gives better visualisation of the parasite. The mouth washes sediment from fresh material revealed $100 \%$ of positivity and clear visualisation of the free form and locomotion of the trophozoites. No stained tecbnique of the smear showed adequate visualisation, presenting the nucleus partially covered by the food vacuoles. In stained preparations by toluidine blue ultrastructure analysis of the morphology of parasite can be observed.

Key-words: Entamoeba gingivalis. Oral protozoa. Periodontal disease. Oral diagnosis.

\section{REFERÊNCIAS BIBLIOGRÁFICAS}

1. Amaral ADF. Sobre a incidência de Entamoeba gingivalis. Revista Paulista de Medicina 35:217, 1949.

2. Bonvini E, De Carneri I. Ricerca di Entamoeba gingivalis e di Tricbomonas tenax nei bambini di etá inferiore ai cinque anni. Giornale di Maladie Infeciosa i Parasitaria 14:361-362, 1962.

3. Cambon M. Étude des protozoaries et di levures de la cavité bucalle chez 509 sujets normaux ou diabetiques. Tese de Doutorado. Faculté de Pharmacie - Université de Clermond I, ClermontFerrand, 1978.

4. Cambon M. Étude des parasites de la cavité buccale chez 45 enfantes de 6 a 15 ans. Pediatrie 34:203-209, 1979.

5. Cambon M. Étude de la fréquence des protozoaries et des levures de la cavité bucalle chez l'homme. Actualité Odontostomatologique 130:279-286, 1980.

6. Cechova L, Leifertová I, Lisa $M$. The incidence of Entamoeba gingiualis in the oral cavity. Medical Acta of North Caroline University 33:549-559, 1987.

7. Child HA. Studies on the ingestion of leucocytes and on mitosis in Entamoeba gingivalis. University California Publication - Zoology 28:1122-1135, 1926. 
Favoreto Junior S, Machado MI. Estudos de freqüência, morfologia e diagnóstico de Entamoeba gingivalis, Gros, 1849. Revista da Sociedade Brasileira de Medicina Tropical 28:379-387, out-dez, 1995.

8. Dao AH, Robinson P, Wong SW. Frequency of Entamoeba gingivalis in human gingival scrapings. American Journal of Periodontology 80:380-382, 1983.

9. Desowitz RS. Oral Parasitology. In: Mc Ghee JRI. (ed) Dental Microbiology, Harper \& Row, Philadelphia, p. 678, 1982.

10. Gannon JT, Linke HAB. Studies on the microflora associated with xenic cultures of Entamoeba gingivalis. Microbios 59:95-100, 1989.

11. Giazzi JF. Contribuição para o estudo dos protozoários bucais $\mathrm{em} 700$ indivíduos da população de Araraquara, Estado de São Paulo. São Paulo.Tese de Doutorado, Faculdade de Saúde Pública da Universidade de São Paulo, São Paulo, 1992.

12. Grisi AM, De Carneri I. Frequenza dell' infezione da Trichomonas tenax entamoeba gingivalis in soggetti in etá giovanili. Parassitologia 5:157-159, 1963.

13. Keller O, Orland FJ, Baird G. Ultrastructure of Entamoeba gingivalis. Journal of Dental Research 46:1010-1018, 1967.

14.Lacour M, Grappin G. Traitement de la gingivostomatite ulcéreuse par le métronidazole. Bulletin de la Societé de Medicine Noire 13:408$410,1968$.

15. Lapierre J, Rousset JJ. L'infestation à protozoaires buccaux. Annales de Parasitologie 48:205-216, 1973.

16. Lyons R, Scholten T. The role of Entamoeba gingivalis gingivalis in periodontal disease. Qintessence Internationale 36:345-352, 1983.

17. Miligi G, Magaudda-Borzi L, Mento G. La frequenza dei portatori di Tricbomonas tenax e di Entamoeba gingivalis in alcune zone della provincia di Messina. Archivi Italiani di Medicine Tropicale 45:95-99, 1964.

18. Omnes $\mathrm{N}$. Contribution à l'étude des atteintes parodontales par le Trichomonas tenax et Entamoeba gingivalis. Tese de Doutorado, Faculdade de Medicina Paris VII, Paris, 1975.
19. Rigueira A. Periodontia Clínica, Editora da Universidade de São Paulo, São Paulo, 1986.

20. Rousset JJ, Laissus B. Premières donnés sur l'enzootie canine à Trichomonas tenax et Entanoeba gingivalis. Leur fréquence en France. Societé Francaise de Biologie 12:1468-1469, 1970.

21. Rousset JJ, Lauvergeat JA. Protozoaires buccaux, enquête épidémiologique. Presse Medicale 79:1495-1496, 1971.

22. Rysky S, Sapelli P. Ultrastruture of oral protozoans. Bulletin of International Research in Stomatological Science 20:229-258, 1977.

23. Takada S, Yamada S,Tsurutami M. Epidemiological observation of protozoa in the human oral cavity. Journal of Osaka Medical Center 9:291-294, 1960.

24. Verri RA, Barros E. Estudos sobre protozoários parasitas da boca humana. Revista Gaúcha de Odontologia 14:28-35, 1966.

25. Verri RA, Salata I. Estudos sobre protozoários parasitas da boca humana - I. Entamoeba gingivalis, Gros, 1849. Revista da Associação Paulista de Cirurgiões Dentistas 15: 252-260, 1961.

26.Wantland WW, Lauer D. Correlation of some oral hygiene variables with age, sex, and incidence of oral protozoa. Journal of Dental Research 49:293296, 1970.

27. Wantland WW, Wantland EM. Studies in human mouth protozoa. Journal of Dental Research 37:949-950, 1958.

28. Wantland WW, Wantland EM, Winquist DL. Collection, identification and cultivation of oral protozoa. Journal of Dental Research 42:1234$1241,1963$.

29. Wollaughin J, Aley S. The biochemistry and functional morphology of the Entamoeba. The Journal of Protozoology 32: 221-240, 1985. 